\title{
The Scholar-Practitioner Dilemma
}

\section{Robert J. Menges}

Most of us who work in professional development are trained as scholar-practitioners. Like other academics, we were schooled to contribute to a discipline and we were expected (if not formally prepared) to practice the profession of teaching.

All scholar-practitioners feel tensions between those roles. Pressure to be productive scholars may reduce attention to teaching. The immediate demands of teaching may rob time from scholarship.

In professional and faculty development positions, expectations and rewards typically weigh more heavily toward practice than toward scholarship. Despite this dilemma, scholarly work in faculty development does get done, and these papers examine how such work is conceived and executed.

This topic had been a concern of the research committee of the Professional and Organizational Network in Higher Education (POD), especially during Bob Young's chairmanship. At the 1980 POD Conference, I organized a committee-sponsored session entitled "On Doing Intellectual Work: Trials, Tribulations, and Triumphs of Research on Faculty Development." The papers prepared for that session were subsequently revised and this monograph makes them more widely available.

\section{Purpose of These Papers}

All of us try to make sense of our experiences and the experience of others. We experiment with alternative conceptualizations; we 
make predictions and seek evidence to support or refute those predictions. Some of us do this formally, professionally, and even get paid for the effort.

This intellectual work is usually shared with others only through its results: articles, training materials, and so on. Seldom do we share descriptions of the processes which give birth to those products. In planning these papers, I asked the authors to describe and reflect on the processes of their intellectual work, in effect to share their intellectual journeys. I suggested that they comment, among other topics, on the following:

a. What issues do I define as central to my intellectual work and how were they sharpened and elaborated over time?

b. What forces shaped the specific research questions I have pursued? To what extent are these forces intrinsic and to what extent are they extrinsic?

c. What factors governed my choice of procedures for gathering and analyzing data?

d. What are my strategies for soliciting/cajoling/seducing the cooperation of those who provide data for my use, and how do I repay them?

e. What standards of scholarship do I require, given the compromises required by research?

f. How do I attempt to influence other researchers and practitioners with the results of my work?

g. How do I protect time and space for formal intellectual work when there is so much else to do?

The first four papers show that despite differing interests, methods and expectations about how their work influences others, the authors' journeys do have some themes in common. These similarities (as well as some differences) are elaborated in the fifth paper.

I hope readers of these papers will be stimulated to think in new ways about scholarly work in professional development. I hope that interest in doing such work will be stimulated as well. 


\section{The Contributors}

Ronald A. Smith is a member of the Department of Mathematics and Director of Learning Development at Concordia University, Montreal. The major theme of his paper is how his original training in mathematics affected his search for conceptual framework and for research methods appropriate to work in faculty development. His journey led from attempting to "apply the pure," under the influence of his mathematics training, to attempting to "purify the applied," that is, to seek conceptual clarity in the unkept world of practice. He discusses in some detail the search for a "lovable" theory and the research which it produced.

Robert E. Young directs the Office of Instructional Development at the University of North Dakota in Grand Forks. Because he was trained in educational psychology, there is more apparent continuity between preparation and present work for him than for Smith. The linking of theory and behavior became both his own intellectual quest and the problem on which he worked with faculty. To illustrate, he describes research with teachers of composition which focuses on their conceptions about teaching.

Rita Weathersby is currently a faculty member in Wittmore School of Business at the University of New Hampshire in Durham. Her formal faculty development experience comes from a variety of previous positions, and her intellectual work has involved the study of adult development, with special reference to students. Broadly stated, her concern is with how one's conceptions of situations change and how such perspective shifts can be understood and facilitated. By describing several of her research efforts, she shows how her own perspectives have been affected as well as how she facilitated developmental transformations in others.

John D. W. Andrews directs the Teaching Assistant Development Program at the University of California, San Diego. His practitioner skills include not only those of teaching and faculty development but also those of psychotherapy. Consequently, he brings a clinical perspective to bear on his activities. Much of his research is stimulated by his own "Marginality," being professionally at the borders of several worlds of content and practice. How marginality can generate 
creative research is well illustrated by his discussion of tension such as that between the experimental and the clinical. A number of his research projects illustrate the effects of tension on problem formulation, research procedures, and the dissemination of findings.

Michael M. Piechowski teaches in the School of Education at Northwestern University. he holds doctorates in both biological science and counseling psychology and pursued a research interest in esthetics. Thus, his expertise spans the physical sciences, the social sciences, and the arts. From that vantage point he traces paths described by the authors and makes some intriguing observations about how their journeys converge and diverge.

\section{Discontinuities Between Preparation and Practice}

Piechowski asserts that the four authors are "struggling with tasks for which can be no formal preparation." While I agree with his observation in the large sense, I also believe that there are identifiable skills of research and scholarship likely to be useful in professional development. Few of us, however, have backgrounds which maximize those skills.

What professional developers do amounts to applied behavioral science. Yet those backgrounds in the physical sciences or humanities may lack familiarity with relevant literature and lack facility with appropriate research methods. (Paradoxically, however, they may be open to fresh insights as they "naively" experience this new field.) Those from the behavioral sciences are disadvantaged in a different way if their training has emphasized studies with experimental controls, large numbers, and quantitative analysis. Unfortunately, these features are seldom feasible in the field in the field of professional development. More appropriate are intensive studies of a few cases with qualitative analysis using such tools as field notes, clinical interviews, and systematic observation. Each of these methods is learnable but its mastery requires the expenditure of significant time and energy.

Little is known about how persons in professional development acquire necessary research skills. It may be that under the press of circumstances there is sufficient time and support for adequate train- 
ing. The alternative is to improvise (but improvisation quickly exceeds competence) or to cease formal scholarly work (one explanation for the relatively small body of literature produced by the field).

This may be the proper time for a study of the preparation and training needs of those in professional development with special attention to their scholarly role. An examination of the available opportunities for high quality training is also timely.

But for now, we move on with the stories of four persons who, despite quite different preparation, have successfully combined scholarship and practice. 